\title{
Numerical Study of Heat Transfer and Flow Bifurcation of CuO Nanofluid in Sudden Expansion Microchannel Using Two-Phase Model
}

\author{
Farhad A. Abbassi*, Mohsen Nazari, Mohammad Mohsen Shahmardan \\ School of Mechanical Engineering, Shahrood University, Shahrood, Iran \\ Email: ^Farhad_a.abbassi@yahoo.com
}

How to cite this paper: Abbassi, F.A., Nazari, M. and Shahmardan, M.M. (2017) Numerical Study of Heat Transfer and Flow Bifurcation of $\mathrm{CuO}$ Nanofluid in Sudden Expansion Microchannel Using Two-Phase Model. Modern Mechanical Engineering, 7, 57-72.

https://doi.org/10.4236/mme.2017.72005

Received: March 13, 2017

Accepted: May 7, 2017

Published: May 10, 2017

Copyright $\odot 2017$ by authors and Scientific Research Publishing Inc. This work is licensed under the Creative Commons Attribution International License (CC BY 4.0).

http://creativecommons.org/licenses/by/4.0/

\begin{tabular}{|c|}
\hline (c) $\underset{\mathrm{EY}}{(1)}$ Open Acc \\
\hline
\end{tabular}

\begin{abstract}
In this paper, laminar forced convection of $\mathrm{CuO}$ nanofluid is numerically investigated in sudden expansion microchannel with isotherm walls and different expansion ratios (ER). An Eulerian two-fluid model is considered to simulate the nanofluid flow inside the microchannel and the governing mass, momentum and energy equations for both phases are solved using the finite volume method. Eulerian-Eulerian two-phase model is very efficient because of considering the relative velocity and temperature of the phases and the nanoparticle concentration distribution. In solving the flow equations for both phases, the SIMPLE algorithm is modified for the coupling of the velocity and pressure and the continuity equations for both phases are combined in order to create the pressure correction equations. However, the Eulerian-Eulerian modeling results show higher heat transfer enhancement in comparison to pure water, so that for a $2 \%$ copper-water nanofluid, it has been observed a $35 \%$ increase of the heat transfer. The heat transfer enhancement increases with increase in Reynolds number and nanoparticle volume concentration, while the pressure drop increases only slightly. An investigation of the expansion ratio of microchannel shows that the average Nusselt number increases with decrease in expansion ratio as well as with increase in Reynolds number. Also, the Bifurcation has been occurred in higher Reynolds number that is different for each expansion ratio of the microchannel.
\end{abstract}

\section{Keywords}

Heat Transfer, Nanofluid, Sudden Expansion Microchannel,

Two-Phase, Eulerian-Eulerian 


\section{Introduction}

The term nanofluid was used by Choi [1] for the first time. After that many researchers continued his works and focused on the modeling of the thermal conductivity of nanofluid [2] [3] [4]. Recently, the concentration is on the heat transfer and fluid flow behavior of nanofluid.

Most experimental studies for nanofluid are done on macro and micro-scales [5] [6] [7] [8]. Wen and Ding [5] studied the heat transfer of $\mathrm{Al}_{2} \mathrm{O}_{3}$-water nanofluid in a copper tube under the constant heat flux. Their measurements in the heat transfer of $\mathrm{Al}_{2} \mathrm{O}_{3}$-water nanofluid showed an enhancement in the entrance region of the tube. They explained that the particle migration reduces the thickness of the thermal boundary layer and causes this behavior in the heat transfer of the nanofluid. Heris et al. [6] investigated $\mathrm{CuO}$-water and $\mathrm{Al}_{2} \mathrm{O}_{3}$-water nanofluids in an annular tube. They compared the results of the experimental study and the homogeneous model and realized the under-estimation of the homogeneous model in the heat transfer enhancement, especially in higher nanoparticle volume concentration. Homogeneous (single phase) and two-phase models are commonly used in the numerical study of the heat transfer and fluid flow of the nanofluid. In single phase model, the velocity and temperature of the base fluid and the particles are the same. Most studies in this field are done by using the single phase model [3] [9] [10]. In the two-phase model, the base fluid and particles are considered as two different phases in despite of the single phase model and both phases have different velocities and temperatures. Also, the interactions between the phases are so important in the governing equations of the two-phase models.

Behzadmehr et al. [11] studied the turbulent convection of the nanofluid in a circular tube by using a two phase mixture model. After comparing their results with an experimental study, they reported that the mixture model has more coincidence to the experimental study compared to the homogeneous model. Mirmasoumi and Behzadmehr [12] also used the two phase mixture model for studying the mixed convection of the nanofluid in a tube. Mirmasoumi and Behzadmehr [13] and Akbarinia and Laur [14] studied the effect of the nanoparticle size on the mixed convection of the nanofluid by the mixture model. An increase in the heat transfer of the nanofluid with decrease in the nanoparticle size was observed in both studies. Kurowski et al. [15] simulated the nanofluid flow by three different mixtures, homogeneous and Eulerian-Lagrangian models in a minichannel. The results of all models were almost the same. Fard et al. [16] used single and two-phase models for studying the heat transfer of the nanofluid inside a tube. They investigated a $0.2 \% \mathrm{CuO}$-water and compared the results with experimental ones and reported that the average relative error between the two-phase model and experimental data was $8 \%$ while it was $16 \%$ for the single phase model.

Mohammad Kalteh et al. [17] investigated the nanofluid forced convection experimentally and numerically inside a wide microchannel heat sink. They used two-phase Eulerian-Eulerian model in numerical method and reported that the 
average Nusselt number increases with increase in Reynolds number and nanoparticle volume concentration. Keshavarz and Mohammadi [18] investigated the thermal performance of $\mathrm{Al}_{2} \mathrm{O}_{3}$-water nanofluid in minichannel heat sink by using single and two-phase models. In their study, it has been observed that the two-phase models have more coincidence with the experimental results in comparison to the single phase model, however, it is not sensible in low volume concentration but by increasing the particle volume concentration up to $1 \%$ or in high Reynolds number, the deviation between the single phase model and the experimental data increases. Shariat et al. [19] studied the impact of nanoparticle mean diameter and the buoyancy force on laminar mixed convection nanofluid flow in an elliptic duct by using two-phase mixture model. They reported that in certain Reynolds and Richardson numbers, the average Nusselt number increases with decrease in the nanoparticle diameter as well as with increase in Richardson number.

In this paper, the nanofluid flow and laminar forced convection in a sudden expansion microchannel with different expansion ratio and isotherm walls are studied by using the Eulerian-Eulerian two-phase model. The governing equations of mass, momentum and energy are discretized using the finite volume method and the modified SIMPLE algorithm is used for solving the flow equations of both phases. Also, the effects of the nanoparticle size and volume concentration and Reynolds number on the average Nusselt number are investigated. Considering the importance of the microfluidic systems and the field of nanofluid heat transfer, the investigation of the flow and heat transfer of nanofluid in a microfluidic device like a sudden expansion microchannel can be so important and practical. In expansion microchannels, the effective hydraulic diameter decreases because of the vortex creation that increases the resistance of the fluid flow. In fact, the sudden expansion microchannels can be used as a microfluidic rectifier, like: Tesla rectifier, simple nozzle/diffuser structures and cascaded nozzle/diffuser structures. These rectifiers are valveless and do the rectification with different flow resistance in the forward flow and the reverse one. On the other hand, two-phase models are proper substitution for a single phase model. Among two-phase models, the Eulerian-Eulerian model has good efficiency because of considering the relative velocity and temperature between phases and the nanoparticle volume concentration distribution.

Numerical investigation of nanofluid flow and heat transfer in a sudden expansion microchannel by using the Eulerian-Eulerian two-phase model and applying the modified SIMPLE algorithm is a new work in the field of nanofluid heat transfer in a microfluidic system.

\section{Governing Equations}

In this study, the geometry is the sudden expansion microchannel with different expansion ratios. Figure 1 is a schematic of the sudden expansion microchannel. The laminar flow of the mixture of water and copper nanoparticles, enters the microchannel with uniform velocity and temperature and the heat transfer 


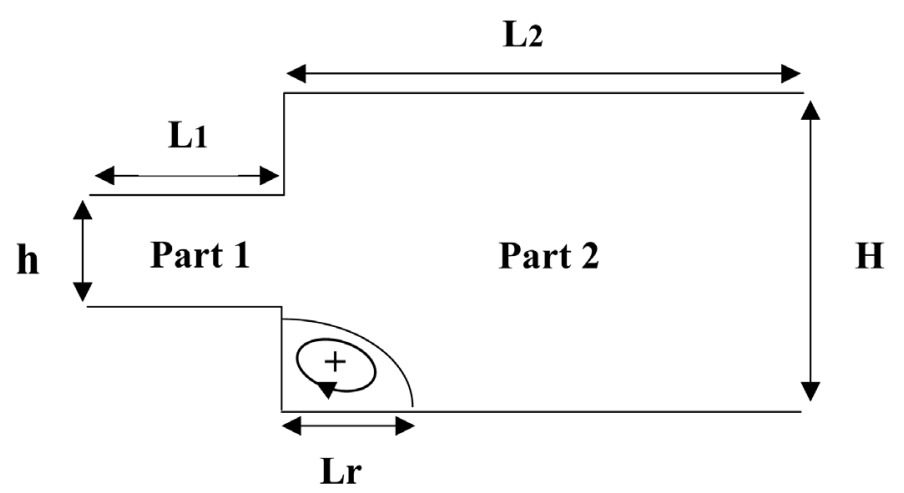

Figure 1. The sudden expansion microchannel.

occurs between the nanofluid and the isothermal walls of the microchannel. The upstream length and height of the microchannel $\left(L_{1}, h\right)$, the downstream length and height of microchannel $\left(L_{2}, h\right)$ and the reattachment length after the expansion region $\left(L_{r}\right)$ are shown in Figure 1.

Considering the Eulerian-Eulerian two-phase model and the steady state, laminar and two-dimensional flow of nanofluid, the governing equations for the base liquid and nanoparticle phases can be written as follows.

\subsection{Continuity Equations}

Continuity equations for solid and liquid phases in the cartesian coordinate system are as follows [20] [21]:

$$
\begin{gathered}
\nabla \cdot\left(\varphi_{l} \rho_{l} \boldsymbol{V}_{l}\right)=0 \\
\nabla \cdot\left(\varphi_{p} \rho_{p} \boldsymbol{V}_{p}\right)=0
\end{gathered}
$$

where $\boldsymbol{V}, \rho$ and $\varphi$ are velocity vector, density and volume concentration, respectively. Subscripts 1 and $\mathrm{p}$ show the base liquid and nanoparticle phases, respectively. Also, for volume concentration of the phases we have

$$
\varphi_{l}+\varphi_{p}=1
$$

\subsection{Momentum Equations}

Momentum equations for solid and liquid phases in cartesian coordinate system are as follows:

$$
\begin{gathered}
\nabla \cdot\left(\varphi_{l} \rho_{l} \boldsymbol{V}_{l} \boldsymbol{V}_{l}\right)=-\varphi_{l} \nabla \cdot P+\nabla \cdot\left(\varphi_{l} \mu_{l} \nabla \boldsymbol{V}_{l}\right)+\boldsymbol{F}_{d}+\boldsymbol{F}_{v m} \\
\nabla \cdot\left(\varphi_{p} \rho_{p} \boldsymbol{V}_{p} \boldsymbol{V}_{p}\right)=-\varphi_{p} \nabla \cdot P+\nabla \cdot\left(\varphi_{p} \mu_{p} \nabla \boldsymbol{V}_{p}\right)+\boldsymbol{F}_{c o l}-\boldsymbol{F}_{d}-\boldsymbol{F}_{v m}
\end{gathered}
$$

where $\boldsymbol{F}_{c o l}, \boldsymbol{F}_{d}, \boldsymbol{F}_{v m}, P$ and $\mu$ are the particle-particle interaction, drag, virtual mass (added mass) forces, pressure and viscosity, respectively. Here, the lift force between the phases can be neglected because of the small size of the nanoparticles and the gravitational force is neglected because of the small size of the microchannel.

The force terms in the momentum equations are defined as

$$
F_{d}=-\beta\left(\boldsymbol{V}_{l}-\boldsymbol{V}_{p}\right)
$$




$$
\begin{gathered}
F_{v m}=0.5 \varphi_{p} \rho_{l} \frac{D}{D t}\left(\boldsymbol{V}_{l}-\boldsymbol{V}_{p}\right) \\
F_{c o l}=G\left(\varphi_{l}\right) \nabla \varphi_{l}
\end{gathered}
$$

The friction coefficient $\beta$, drag coefficient $C_{d}$, the particle-particle interaction modulus $G$ and the particle Reynolds namber are

$$
\begin{gathered}
\beta=\frac{3}{4} C_{d} \frac{\varphi_{l}\left(1-\varphi_{l}\right)}{d_{p}}\left|\boldsymbol{V}_{l}-\boldsymbol{V}_{p}\right| \varphi_{l}^{-2.65} \\
C_{d}= \begin{cases}\frac{24}{R e_{p}}\left(1+0.15 R e_{p}^{0.697}\right), & R e_{p}<1000 \\
0.44, & R e_{p} \geq 1000\end{cases} \\
G=1.0 \exp \left(-600\left[\varphi_{l}-0.376\right]\right) \\
\operatorname{Re}_{p}=\frac{\varphi_{l} \rho_{l}\left|\boldsymbol{V}_{l}-\boldsymbol{V}_{p}\right| d_{p}}{\mu_{l}}
\end{gathered}
$$

Here, $d_{p}$ is the nanoparticle diameter.

Equation (9) is valid for $\varphi_{p}>0.8$. Also, it should be considered that Equations (8)-(14) are not obtained for nano-sized particles. But, they can be used for nanoparticles because of the lack of the proper correlations for nano-sized particles [22].

\subsection{Energy Equations}

The base fluid and particle phases are considered as incompressible fluids and the viscous dissipation and radiation are neglected. So, the energy equations in cartesian coordinate system can be written as

$$
\begin{gathered}
\nabla \cdot\left(\varphi_{l} \rho_{l} C_{p l} V_{l} T_{l}\right)=\nabla \cdot\left(\varphi_{l} k_{e f f, l} \nabla T_{l}\right)-h_{v}\left(T_{l}-T_{p}\right) \\
\nabla \cdot\left(\varphi_{p} \rho_{p} C_{p_{p}} V_{p} T_{p}\right)=\nabla \cdot\left(\varphi_{p} k_{e f f, p} \nabla T_{p}\right)+h_{v}\left(T_{l}-T_{p}\right)
\end{gathered}
$$

Here, $T, k_{e f f}, C_{p}$ and $h_{v}$ are the temperature, effective thermal conductivity, heat capacity at constant pressure and volume interphase heat transfer coefficient, respectively. For spherical nanoparticles $h_{v}$ can be calculated as

$$
h_{v}=\frac{6\left(1-\varphi_{l}\right)}{d_{p}} h_{p}
$$

Here, $h_{p}$ is the fluid-particle heat transfer coefficient that is obtained from experimental correlations.

$$
N u_{p}=\frac{h_{p} d_{p}}{k_{l}}=2+1.1 \operatorname{Re}_{p}^{0.6} \operatorname{Pr}^{\frac{1}{3}}
$$

where $\operatorname{Pr}$ is the base liquid Prandtl number.

The effective thermal conductivities for both phases are

$$
k_{e f f, l}=\frac{k_{b, l}}{\varphi_{l}}
$$




$$
k_{e f f, p}=\frac{k_{b, p}}{\varphi_{p}}
$$

where

$$
\begin{gathered}
k_{b, l}=\left(1-\sqrt{\left(1-\varphi_{l}\right)}\right) k_{l} \\
k_{b, p}=\sqrt{\left(1-\varphi_{l}\right)}(\omega A+[1-\omega] \Gamma) k_{l} \\
\Gamma=\frac{2}{\left(1-\frac{B}{A}\right)}\left\{\frac{B(A-1)}{A\left(1-\frac{B}{A}\right)^{2}} \ln \left(\frac{A}{B}\right)-\frac{(B-1)}{\left(1-\frac{B}{A}\right)}-\frac{B+1}{2}\right\} \\
B=1.25\left(\frac{\left[1-\varphi_{l}\right]}{\varphi_{l}}\right)^{\frac{10}{9}}
\end{gathered}
$$

For spherical nanoparticles

$$
\begin{gathered}
A=\frac{k_{p}}{k_{l}} \\
\omega=7.26 \times 10^{-3}
\end{gathered}
$$

Equations (18)-(25) are not obtained for nano-sized particles. But these correlations are used because of the lack of the appropriate correlations for nanosized particles [22].

The Nusselt number is calculated from the temperature difference between the nanofluid mean temperature and the microchannel walls:

$$
N u=\frac{\left(h D_{h}\right)}{k_{l}}=q^{\prime \prime} D_{h} / k_{l}\left(T_{w}-T_{m}\right)
$$

Here, $q^{\prime \prime}, h$ and $D_{h}$ are the wall convective heat transfer flux, convective heat transfer coefficient and the microchannel hydraulic diameter, respectively. The mean temperature of the nanofluid is calculated as follow

$$
T_{m}=\frac{\sum_{i=1}^{p}\left(\int \rho_{i} u_{i} c_{p i} T_{i} \mathrm{~d} A\right)}{\sum_{i=1}^{p}\left(\int \rho_{i} u_{i} c_{p i} \mathrm{~d} A\right)}
$$

where the integration is applied on the microchannel cross section.

According to the Equations (15) and (16), the wall convective heat transfer flux can be obtained as

$$
q^{\prime \prime}=\left(\varphi_{l} k_{e f f, l} \frac{\partial T_{l}}{\partial y}\right)_{w}+\left(\varphi_{p} k_{e f f, p} \frac{\partial T_{p}}{\partial y}\right)_{w}
$$

Considering the local heat transfer coefficient, the average heat transfer coefficient is

$$
\bar{h}=\frac{1}{L} \int_{0}^{L} h \mathrm{~d} x
$$

\subsection{Non-Dimensionalization}

The non-dimensional parameters using in converting the governing equations 
are as follows:

$$
\begin{aligned}
& X=\frac{x}{D_{h}}, Y=\frac{y}{D_{h}}, U_{i}=\frac{u_{i}}{u_{i n}}, V_{i}=\frac{v_{i}}{u_{i n}}, P=\frac{p-p_{i n}}{\rho_{l} u_{i n}^{2}}, \\
& \theta_{i}=\frac{T_{i}-T_{i n}}{T_{w}-T_{i n}}, \operatorname{Re}_{i}=\frac{u_{i n} D_{h} \rho_{i}}{\mu_{i}}, \operatorname{Pr}_{i}=\frac{\rho_{i} C_{p i} v_{i}}{k_{i}}
\end{aligned}
$$

where $i=1, p$ indicates the liquid and particle phases.

\subsection{Boundary Conditions}

At the inlet, the mixture of water and copper nanoparticles enters the sudden expansion microchannel with the same uniform axial velocity. At the outlet, the velocity boundary condition is considered for the outflow of the both phases. In this study, the non-slip boundary condition at the walls is assumed for both phases.

For thermal boundary conditions, the microchannel walls are isothermal and the outflow temperature boundary condition is considered for both phases. Because the length of the microchannel is too long, the variations of the outflow velocity and temperature are assumed as follow

$$
\frac{\partial u}{\partial x}=0, \frac{\partial v}{\partial x}=0, \frac{\partial T}{\partial x}=0
$$

\section{Numerical Method}

In this study, the non-dimensional forms of the governing equations are discretized by the finite volume method. The first order upwind scheme is used for discretizing the convection-diffusion term. After discretization, the governing equations are converted to a set of algebric equations that is solved iteratively and the SIMPLE algorithm is used for the pressure-velocity coupling [23] [24]. For using this algorithm, the pressure correction equation is obtained from the combination of the continuity equations of the base fluid and particle phases. In fact, combining the continuity equations for both phases causes a new pressure correction equation that modifies the SIMPLE algorithm and the under-relaxation coefficients are used for velocity and pressure in order to accelerate the convergence of the algorithm. In this algorithm, the source term of the pressure correction equation is considered as the convergence criterion. In this study, the iteration is continued until the convergence criterion becomes smaller than $10^{-6}$ in all cells.

\section{Grid Independence Study}

To investigate that the results are independent from the number of grid points, the average Nusselt number is calculated for various numbers of grid points and Reynolds numbers. Table 1 and Figure 2 show the average Nusselt numbers for four different numbers of grid points and $R e=100$. It can be seen that the average Nusselt numbers between the 3 and 4 grids have a negligible difference, so the grid 3 is selected for this study. 


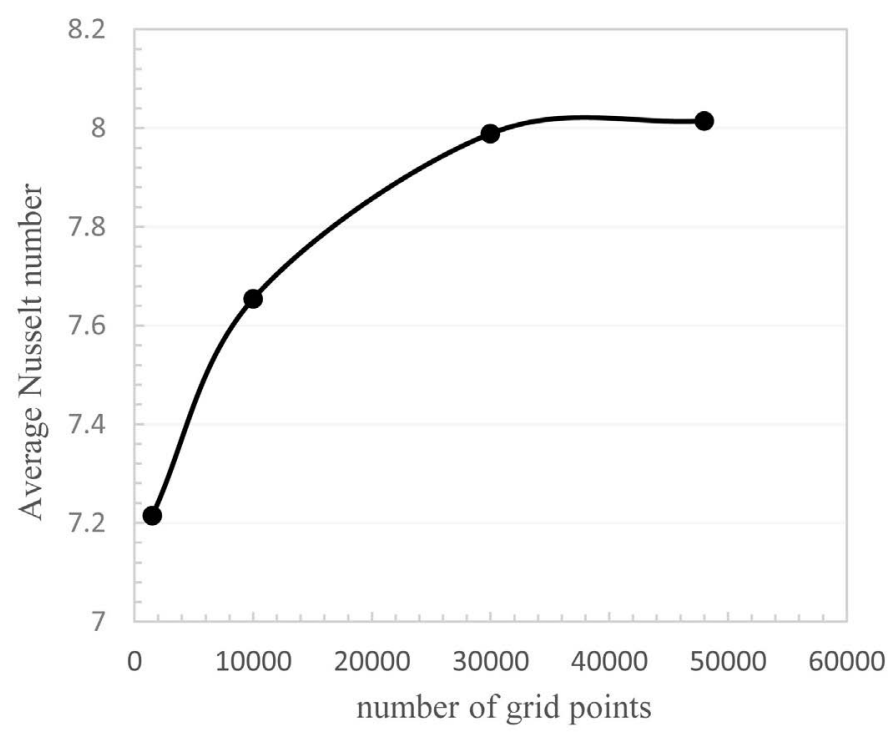

Figure 2. The average Nusselt number versus number of grid points.

Table 1. Grid-independency study results for $\varphi_{p}=0.01, E R=3$ and $R e=100$.

\begin{tabular}{ccccc}
\hline Grid & $\begin{array}{c}1 \\
N_{y} \times N_{x}\end{array}$ & $\begin{array}{c}2 \\
N_{y} \times N_{x}\end{array}$ & $\begin{array}{c}3 \\
N_{y} \times N_{x}\end{array}$ & $\begin{array}{c}4 \\
N_{y} \times N_{x}\end{array}$ \\
\hline Part1 & $10 \times 15$ & $20 \times 50$ & $30 \times 100$ & $40 \times 120$ \\
Part2 & $30 \times 45$ & $60 \times 150$ & $90 \times 300$ & $120 \times 360$ \\
All cells & 1500 & 10,000 & 30,000 & 48,000 \\
Average Nusselt & 7.214875 & 7.654121 & 7.988713 & 8.014657 \\
\hline
\end{tabular}

\section{Validation}

Because of the lack of the experimental studies for nanofluid flow in a sudden expansion microchannels, the reattachment length for the pure water $\left(\varphi_{p}=0.0\right)$ at different Reynolds numbers is calculated and compared to Scott et al. [25] results in order to investigate the accuracy of the code. Table 2 and Figure 3 show the reasonable coincidence between the different amounts of the reattachment length of these two studies for $E R=3$ and the maximum deviation is less than $4 \%$.

\section{Results and Discussion}

\subsection{The Viscosity of the Solid Phase}

One of the important parameter in this two phase study is the solid viscosity $\left(\mu_{p}\right)$. In fact, the solid viscosity is the virtual viscosity that must be defined correctly in this model. There is not much experimental data for this viscosity in a solid-liquid two phase mixture, so the trial and error method is used for obtaining the proper value for the solid viscosity. This viscosity appears in the Reynolds number of the solid phase, thus $\mu_{p}$ is calculated for the different Reynolds number of the solid phase until the velocity profile of this numerical solu- 


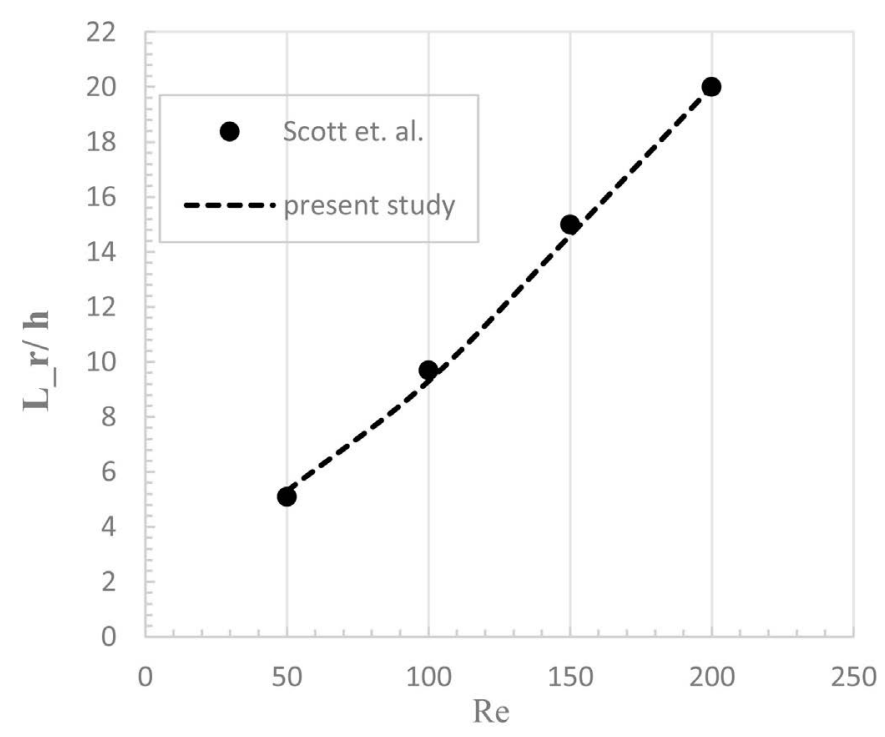

Figure 3. Comparison between reattachment length of this study and Scott's one for different Reynolds number.

Table 2. Comparison between reattachment length of this study and Scott's one.

\begin{tabular}{ccc}
\hline Reynolds number $(R e)$ & Reattachment length $\frac{L_{r}}{h}$ & Reattachment length $\frac{L_{r}}{h} \quad[25]$ \\
\hline 50 & 5.3 & 5.1 \\
100 & 9.3 & 9.7 \\
150 & 14.6 & 15 \\
200 & 20 & 20 \\
\hline
\end{tabular}

tion has an appropriate coincidence with it's analytical solution profile. Consequently, $\mu_{p}$ is obtained from the trial and error method and the Reynolds number of the solid phase. Table 3 shows the sensitivity of the Nusselt number to the solid viscosity for $\varphi_{p}=0.01, E R=3, R e=100$ and $d_{p}=100 \mathrm{~nm}$.

It can be seen that the changes of the Nusselt number is small when $\mu_{p}$ changes. So, the amount of the solid viscosity is not so effective on the results and it is not necessary to find the exact amount of this viscosity. Also, Saffaraval et al. [18] reported the same result about the particle viscosity. The amount of the solid viscosity is considered to be 0.089 Pa.s in this study.

\subsection{Force Terms in the Momentum Equations}

The momentum equation has three interphase forces including virtual mass, particle-particle interaction and drag forces. In Table 4, the average Nusselt number is investigated for $d_{p}=100 \mathrm{~nm}, R e=100$ and different conditions of the force terms. It can be seen that the particle-particle interaction and vitual mass forces are not effective on the average Nusselt number, however, the drag force changes the average Nusselt number slightly. Neglecting the drag term causes the average Nusselt number increase, especially in the higher nanoparticle 
Table 3. Average Nusselt number on the solid viscosity for $\varphi_{p}=0.01, E R=3$, $R e=100$ and $d_{p}=100 \mathrm{~nm}$.

\begin{tabular}{cc}
\hline Solid viscosity & Average Nusselt \\
\hline 0.001 & 7.889133 \\
0.005 & 7.964714 \\
0.008 & 7.892112 \\
0.01 & 7.938243 \\
0.03 & 7.953711 \\
0.07 & 7.981838 \\
0.089 & 7.988713 \\
0.1 & 8.004554 \\
\hline
\end{tabular}

Table 4. Effect of the force terms on the average Nusselt number for $R e=100$, $E R=3$ and $d_{p}=100 \mathrm{~nm}$.

\begin{tabular}{ccccc}
\hline $\begin{array}{c}\text { Volume } \\
\text { concentration (\%) }\end{array}$ & $\begin{array}{c}\text { Considering } \\
\text { all force term }\end{array}$ & Neglecting $F_{d}$ & Neglecting $F_{c o l}$ & Neglecting $F_{v m}$ \\
\hline 1 & 7.988713 & 8.02481 & 7.98862 & 7.98864 \\
2 & 8.193648 & 8.28713 & 8.19353 & 8.19349 \\
3 & 8.411941 & 8.54164 & 8.41193 & 8.41191 \\
4 & 8.633981 & 8.81341 & 8.63378 & 8.63392 \\
5 & 8.856696 & 9.09733 & 8.85658 & 8.85668 \\
\hline
\end{tabular}

volume concentrations. According to Table 4, by neglecting the drag term at $\varphi_{p}=0.01$, the average Nusselt number increases 0.03 and it increases 0.24 at $\varphi_{p}=0.05$. Consequently, the particle-particle interaction and virtual mass forces can be neglected in the mathematical models of nanofluid.

\subsection{Enhancement of the Nanofluid Heat Transfer in Comparison to the Pure Water}

Figure 4 shows the increase of the average Nusselt number of the nanofluid in comparison to the pure water for different nanoparticle volume concentration. The results show the non-linearly increase in the nanofluid heat transfer enhancement when the nanoparticle volume concentration increases. In fact, the nanofluid heat transfer enhancement is caused by the presence of the copper nanoparticles that increases the thermal conductivity coefficient of the fluid. At $\varphi_{p}=0.02$ it has been observed that the percentage enhancement in the average Nusselt number at $R e=100$ is $7.6 \%$ more than the corresponding percentage at $R e=50$.

The enhancement of the nanofluid heat transfer in comparison to the pure water can be seen from Figure 5 that the coefficient of performance (COP) increases with an increase in the nanoparticle volume concentration for every Reynolds number. Another important observation in Figure 5 is that the lower 


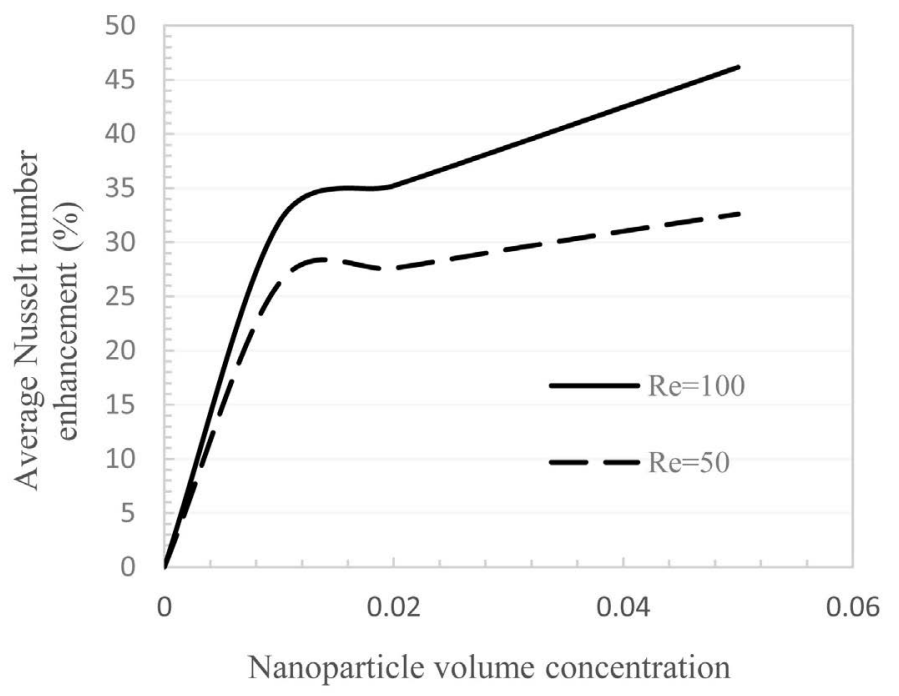

Figure 4. Comparison of percentage enhancement in average Nusselt number with respect to pure water for different volume concentrations and $E R=3$.

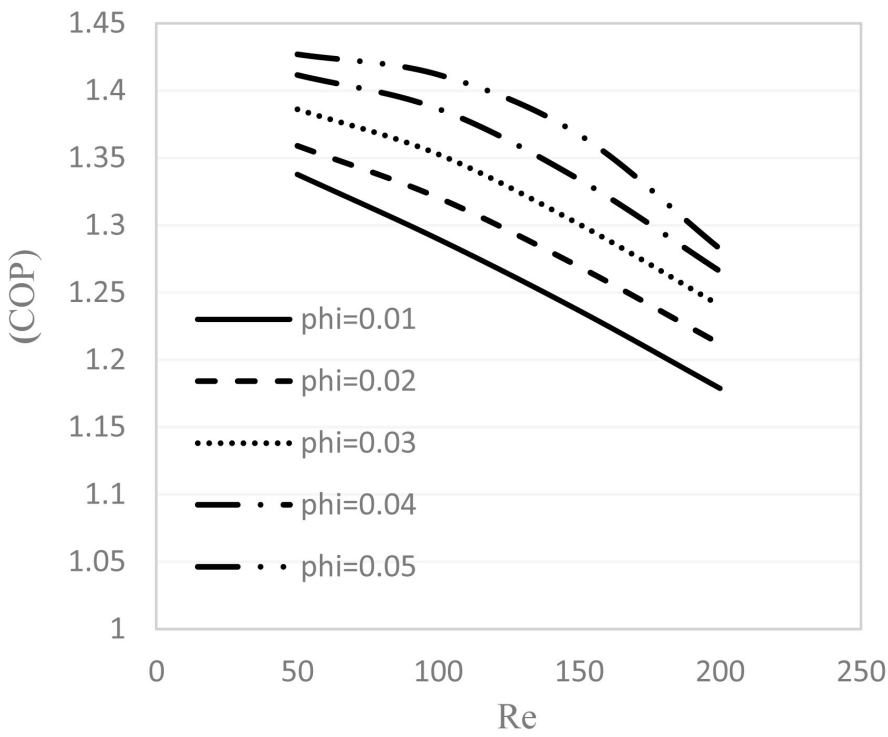

Figure 5. Coefficient of performance of the nanofluid versus Reynolds number for different nanoparticle volume concentration, $E R=3$ and $d_{p}=100 \mathrm{~nm}$.

Reynolds number affects more on increasing the COP for a definite nanoparticle volume concentration. Here, the COP of the nanofluid is obtained as

$$
\mathrm{COP}=\left(\frac{N u_{n f}}{N u_{p w}}\right) /\left(\frac{\Delta p_{n f}}{\Delta p_{p w}}\right)
$$

where subscripts $\mathrm{nf}$ and pw show the nanofluid and pure water, respectively.

\subsection{Expansion Ratio Effect on the Nanofluid Heat Transfer and Flow}

Figure 6 illustrates the pressure drop for $d_{p}=100 \mathrm{~nm}$ when the expansion ratio of the microchannel changes. From Figure 6 it has been observed that the 


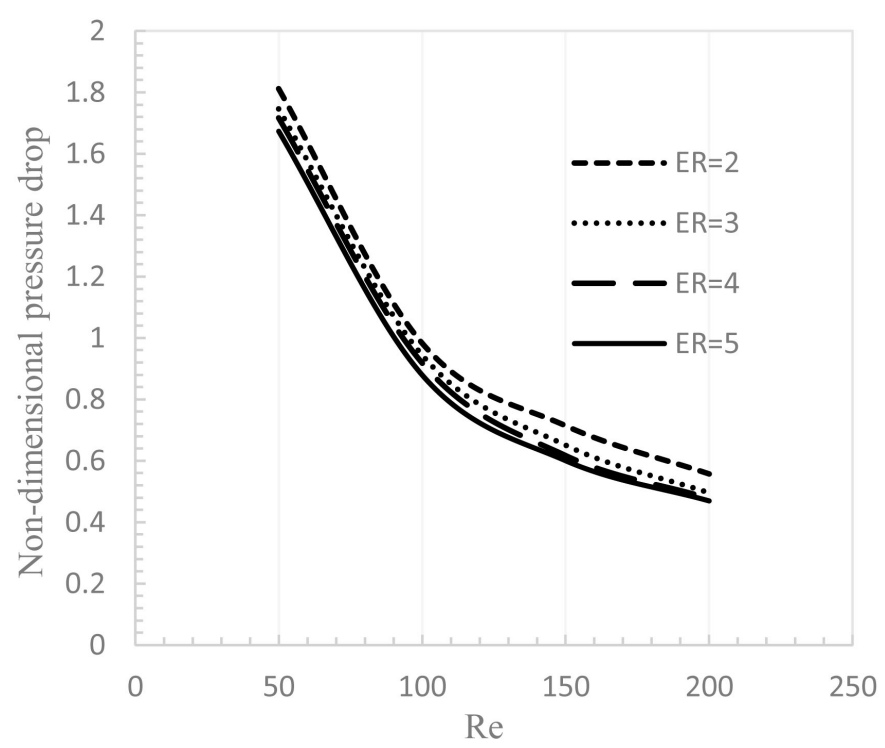

Figure 6. Non-dimensional pressure drop versus Reynolds number for different expansion ratio and $d_{p}=100 \mathrm{~nm}$.

pressure drop increases with decrease of the expansion ratio of the microchannel but it is small for all Reynolds numbers.

Figure 7 depicts the effect of Reynolds number and the expansion ratio of the microchannel on the average Nusselt number for $d_{p}=100 \mathrm{~nm}$. It has been observed that the average Nusselt number increases with increase in Reynolds number and decrease in the expansion ratio of the microchannel. Reynolds number increases the convection effects but the increase of the expansion ratio decreases the pressure drop and makes the larger recirculation zone that decreases the convection effects and causes the lower heat transfer.

\subsection{Bifurcation}

The increasing of the Reynolds number increases the expansion pressure. The pressure forces dominate the viscous force in the critical Reynolds number where the viscous force cannot hold the flow structure in a symmetric couple of vortexes anymore. In this case, the reattachment length of the upper wall decreases when the reattachment length of the lower one increases and the bifurcation of the reattachment length occurs in the critical Reynolds number. Figure 8 shows that the critical Reynolds number decreases with increase in expansion ratio of the microchannel and the bifurcation point moves to the left side. It can be seen from Figure 8 that the trinity occurs in the second critical Reynolds number for the reattachment length with more increase in the Reynolds number.

The trend of the first critical Reynolds number versus expansion ratio is a straight line. In Figure 9, a correlation for the first critical Reynolds number and expansion ratio is obtained by using the linear regression.

The first and second critical Reynolds numbers for different expansion ratios are shown in Table 5. 


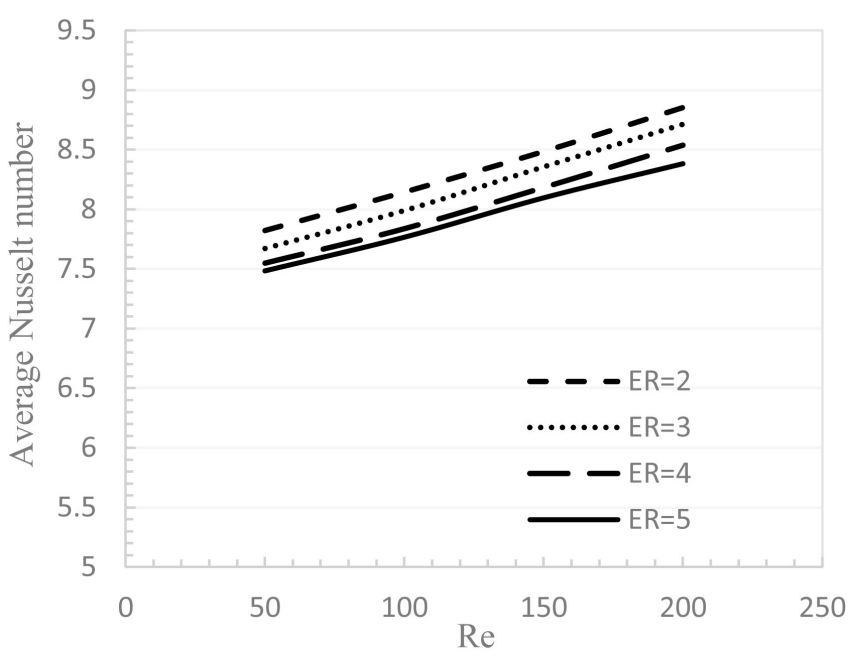

Figure 7. Average Nusselt number versus Reynolds number for different expansion ratio and $d_{p}=100 \mathrm{~nm}$.

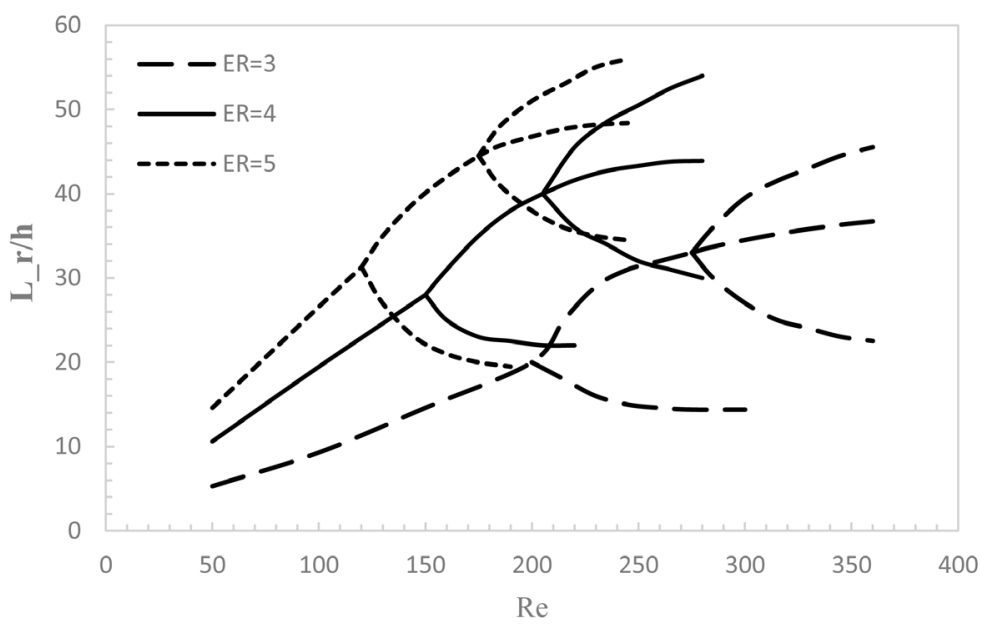

Figure 8. Comparison of the bifurcation for different expansion ratios.

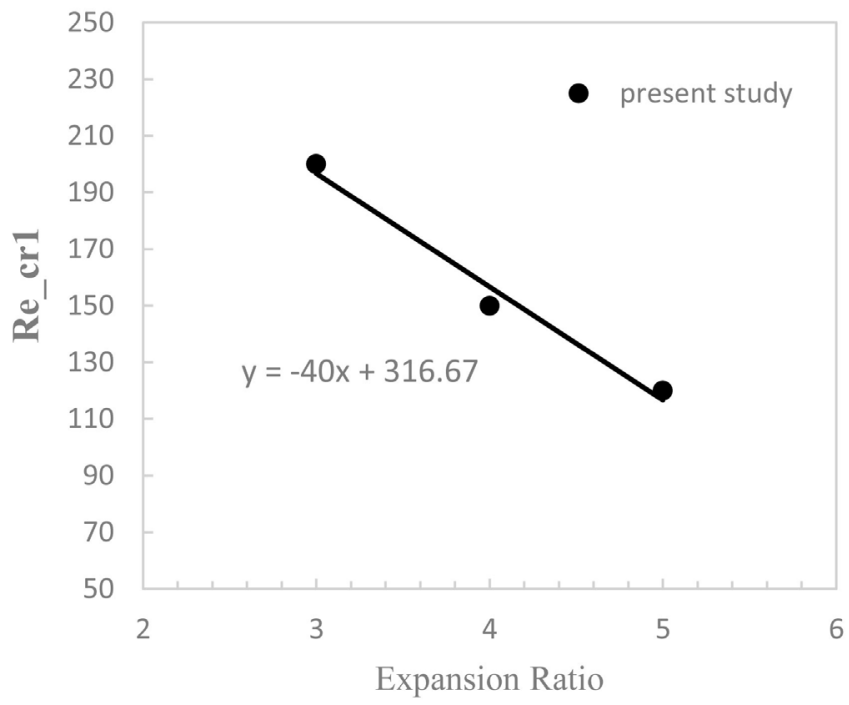

Figure 9. Linear regression for the first critical Reynolds number. 
Table 5. The first and second critical Reynolds numbers for different expansion ratios.

\begin{tabular}{cccc}
\hline Critical Reynolds number & ER $=3$ & ER $=4$ & ER $=5$ \\
\hline $\operatorname{Re}_{C r 1}$ & 200 & 150 & 120 \\
$\operatorname{Re}_{c r 2}$ & 275 & 205 & 175 \\
\hline
\end{tabular}

\section{Conclusion}

A two-phase model is considered to simulate the nanofluid flow inside the microchannel and among two-phase models, Eulerian-Eulerian model is very efficient because of considering the relative velocity and temperature of the phases and the nanoparticle concentration distribution. The governing mass, momentum and energy equations for both phases are solved using the finite volume method. In solving the flow equations for both phases, the SIMPLE algorithm is modified for the coupling of the velocity and pressure and the continuity equations for both phases are combined in order to create the pressure correction equations. However, the Eulerian-Eulerian modeling results show higher heat transfer enhancement in comparison to pure water, so that for a $2 \%$ copper-water nanofluid, it has been observed a $35 \%$ increase of the heat transfer. The average nusselt number increases with increase in Reynolds number and nanoparticle volume concentration and decrease of the expansion ratio of the microchannel. For a constant volume concentration, the lower Reynolds number causes the larger average Nusselt number ratio. The critical Reynolds number for bifurcation decreases with increase in the expansion ratio of the microchannel. The importance and developments of microfluidic devices, like expansion microchannel, has made the investigation of the flow and the heat transfer of nanofluid in sudden expansion microchannel so important and practical. On the other hand, the two-phase models can be used instead of single phase model very well.

\section{References}

[1] Choi, S.U.S. (1995) Enhancing Thermal Conductivity of Fluids with Nanoparticles. In: Siginer, D.A. and Wang, H.P., Eds., Developments and Applications of NonNewtonian Flows, ASME, Vol. 66, 99-105.

[2] Xuan, Y., Li, Q. and Hu, W. (2003) Aggregation Structure and Thermal Conductivity of Nanofluids. AIChE Journal, 49, 1038-1043.

[3] Koo, J. and Kleinstreuer, C. (2004) A New Thermal Conductivity Model for Nanofluids. Journal of Nanoparticle Research, 6, 577-588. https://doi.org/10.1007/s11051-004-3170-5

[4] Feng, Y., Yu, B., Xu, P. and Zou, M. (2007) The Effective Thermal Conductivity of Nanofluids Based on the Nanolayer and the Aggregation of Nanoparticles. Journal of Physics D: Applied Physics, 40, 3164-3171. https://doi.org/10.1088/0022-3727/40/10/020

[5] Wen, D. and Ding, Y. (2004) Experimental Investigation into Convective Heat Transfer of Nanofluids at the Entrance Region under Laminar Flow Conditions. International Journal of Heat and Mass Transfer, 47, 5181-5188.

[6] Heris, S.Z., Etemad, S.Gh. and Esfahany, M.N. (2006) Experimental Investigation of 
Oxide Nanofluids Laminar Flow Convective Heat Transfer. International Communications in Heat and Mass Transfer, 33, 529-535.

[7] Jung, J.Y., Oh, H.S. and Kwak, H.Y. (2009) Forced Convective Heat Transfer of Nanofluids in Microchannels. International Journal of Heat and Mass Transfer, 52, 466-472.

[8] Wu, X., Wu, H. and Cheng, P. (2009) Pressure Drop and Heat Transfer of $\mathrm{Al}_{2} \mathrm{O}_{3}$ $\mathrm{H}_{2} \mathrm{O}$ Nanofluids through Silicon Microchannels. Journal of Micromechanics and Microengineering, 19, 105-112.

[9] Li, J. and Kleinstreuer, C. (2008) Thermal Performance of Nanofluid Flow in Microchannels. International Journal of Heat and Fluid Flow, 29, 1221-1232.

[10] Santra, A.K., Sen, S. and Chakraborty, N. (2009) Study of Heat Transfer Due to Laminar Flow of Copper-Water Nanofluid through Two Isothermally Heated Parallel Plates. International Journal of Thermal Sciences, 48, 391-400.

[11] Behzadmehr, A., Saffar-Avval, M. and Galanis, N. (2007) Prediction of Turbulent Forced Convection of a Nanofluid in a Tube with Uniform Heat Flux Using a Two Phase Approach. International Journal of Heat and Fluid Flow, 28, 211-219.

[12] Mirmasoumi, S. and Behzadmehr, A. (2008) Numerical Study of Laminar Mixed Convection of a Nanofluid in a Horizontal Tube Using Two-Phase Mixture Model. Applied Thermal Engineering, 28, 717-727.

[13] Mirmasoumi, S. and Behzadmehr, A. (2008) Effect of Nanoparticles Mean Diameter on Mixed Convection Heat Transfer of a Nanofluid in a Horizontal Tube. International Journal of Heat and Fluid Flow, 29, 557-566.

[14] Akbarinia, A. and Laur, R. (2009) Investigating the Diameter of Solid Particles Effects on a Laminar Nanofluid Flow in a Curved Tube Using a Two Phase Approach. International Journal of Heat and Fluid Flow, 30, 706-714.

[15] Kurowski, L., Chmiel-Kurowska, K. and Thullie, J. (2009) Numerical Simulation of Heat Transfer in Nanofluids. Computer Aided Chemical Engineering, 26, 967-972.

[16] Fard, M.H., Esfahany, M.N. and Talaie, M.R. (2010) Numerical Study of Convective Heat Transfer of Nanofluids in a Circular Tube Two-Phase Model versus Single-Phase Model. International Communications in Heat and Mass Transfer, 37, 91-97.

[17] Kalteh, M., Saffar-Avval, M., Abbassi, A., Frijns, A., Darhuber, A. and Harting, J. (2012) Experimental and Numerical Investigation of Nanofluid Forced Convection inside a Wide Microchannel Heat Sink. Applied Thermal Engineering, 36, 260-268.

[18] Moraveji, M.K. and Ardehali, R.M. (2013) CFD Modeling (Comparing Single and Two-Phase Approaches) on Thermal Performance of $\mathrm{Al}_{2} \mathrm{O}_{3}$ /Water Nanofluid in Mini-Channel Heat Sink. International Communications in Heat and Mass Transfer, 44, 157-164.

[19] Shariat, M., Mokhtari, R., Akbarinia, A., Rafee, R. and Sajjadi, S.M. (2014) Impact of Nanoparticle Mean Diameter and the Buoyancy Force on Laminar Mixed Convection Nanofluid Flow in an Elliptic Duct Employing Two Phase Mixture Model. International Communications in Heat and Mass Transfer, 50, 15-24.

[20] Hao, Y.L. and Tao, Y.X. (2004) A Numerical Model for Phase-Change Suspension Flow in Microchannels. Numer. Numerical Heat Transfer, Part A: Applications, 46, 55-77.

[21] (2006) Fluent 6.3 User's Guide. Fluent Inc.

[22] Saffar-Avval, M., Kalteh, M., Abbassi, A. and Harting, J. (2011) Eulerian-Eulerian Two-Phase Numerical Simulation of Nanofluid Laminar Forced Convection in a Microchannel. International Journal of Heat and Fluid Flow, 32, 107-116.

[23] Patankar, S.V. (1980) Numerical Heat Transfer and Fluid Flow. Hemisphere, 
Washington DC.

[24] Versteeg, H.K. and Malalasekera, W. (1995) An Introduction to Computational Fluid Dynamics the Finite Volume Method. Longman Scientific and Technical, England.

[25] Scott, P.S. and Mirza, F.A. (1986) A Finite Element Analysis of Laminar Flows through Planar and Axisymmetric Abrupt Expansions. Computers \& Fluids, 14, 423-432.

Submit or recommend next manuscript to SCIRP and we will provide best service for you:

Accepting pre-submission inquiries through Email, Facebook, LinkedIn, Twitter, etc. A wide selection of journals (inclusive of 9 subjects, more than 200 journals)

Providing 24-hour high-quality service

User-friendly online submission system

Fair and swift peer-review system

Efficient typesetting and proofreading procedure

Display of the result of downloads and visits, as well as the number of cited articles Maximum dissemination of your research work

Submit your manuscript at: http://papersubmission.scirp.org/

Or contact mme@scirp.org 